\title{
Natural history of Hartnup disease
}

\author{
BRIDGET WILCKEN, J. S. YU, AND D. A. BROWN \\ From the Oliver Latham Laboratory, North Ryde Psychiatric Centre, and the Royal Alexandra Hospital \\ for Children, Sydney, Australia
}

SUMmaRY Hartnup disease was diagnosed in 12 children and 3 of their 15 sibs in the course of routine urine screening of 6-week-old infants in New South Wales. These children were followed for up to 8 years, during which time there were only two clinical episodes which might be ascribed to Hartnup disease. The mental development of all the children was normal. 10 had height centiles less than the midparent height centiles, while 4 had centiles equal to or above the midparent centiles.

The study shows that in children with Hartnup disease in Australia symptoms are very uncommon. Mental development is normal, and heights are possibly slightly below that expected. Hartnup disease has an incidence of approximately 1 in 33000 in New South Wales.

Hartnup disease is a disorder of renal tubular and intestinal transport of amino acids, with reported clinical association with pellagra-like rash and ataxia. Since the Hartnup family was first described by Baron and his colleagues (1956) over 50 cases have been reported. Jepson (1972) has reviewed 43 of these, most of whom were identified by the clinical manifestations. We report the follow-up of a group of children with Hartnup disease identified by newborn screening of urine.

\section{Methods}

Over a 9-year period urine samples from 830000 6-week-old babies in New South Wales, $85 \%$ of the newborn population, were examined by one-dimensional paper chromatography (Turner and Brown, 1970; Wilcken et al., 1973). Hartnup disease was diagnosed in babies who had a constant gross aminoaciduria which involved serine, threonine, glutamine, asparagine, alanine, valine, leucine, isoleucine, phenylalanine, tyrosine, tryptophan, and histidine. (Increased excretion of indolic compounds was also present, but this abnormality was often not seen in early infancy.)

The children with a Hartnup-like aminoaciduria were seen yearly or more often. They were assessed clinically, and their parents were questioned specifically about the occurrence of rashes, effect of sunlight, unsteadiness of gait, and any illness keeping

Received 30 April 1976 the child in bed for one day or longer. They were asked about any medication the child had received, the diet, and any vitamin preparations used. Achievement of milestones was recorded, and parents were asked to rate development of the child as slower than, the same as, or quicker than that of unaffected sibs. Those with school-age children were asked which grade the child was in, and whether he or she was below average, average, or above average in the class. Urinary amino acids and indoles were examined at each visit by paper chromatography. Renal clearance studies for amino acids were carried out in 6 cases, and urinary and plasma amino acids estimated on a Beckman Unichrome amino acid analyser using standard methods. One child was investigated biochemically on several occasions but was never seen by the authors. Information was also obtained from the family doctor by means of a specific questionnaire, as outlined above.

Height and weight of the affected children were measured, as was the height of some of the sibs. Height without shoes of other sibs and of the parents was reported by the parents, though no correction was made for parents' age, most being under 45. The children's height centiles and the midparent height centiles were calculated using tables prepared by Tanner et al. (1970).

Six children were treated with nicotinamide 25 mg daily or weekly. One child stopped treatment during the observation period. The remainder were untreated (see Table). Institution of treatment depended solely upon the clinician looking after the patient. 
Table Clinical details of patients with Hartnup disease

\begin{tabular}{|c|c|c|c|c|c|c|}
\hline $\begin{array}{l}\text { Case no. } \\
\text { and sex }\end{array}$ & $\begin{array}{l}\text { Age at last review* } \\
\text { (years) }\end{array}$ & Symptoms & $\begin{array}{l}\text { Weight } \\
\text { centile }\end{array}$ & $\begin{array}{l}\text { Height } \\
\text { centile }\end{array}$ & $\begin{array}{l}\text { Midparent } \\
\text { height } \\
\text { centile }\end{array}$ & $\begin{array}{l}\text { Treatment } \\
\text { nicotinamide } \\
25 \mathrm{mg}\end{array}$ \\
\hline $\left.\begin{array}{ll}\begin{array}{l}1 \\
2\end{array} & \mathrm{M} \\
3 & \mathrm{~F} \\
4 & \mathrm{M} \\
5 & \mathrm{M}\end{array}\right\}$ & $\begin{array}{r}8 \cdot 5 \\
13 \cdot 7 \\
8 \cdot 1 \\
5 \cdot 3 \\
11 \cdot 6 \\
3 \cdot 5 \\
3 \cdot 4 \\
2 \cdot 75\end{array}$ & $\begin{array}{l}\text { Nil } \\
\text { Nil } \\
\text { Nil } \\
\text { Mild diarrhoea in infancy } \\
\text { Mild diarrhoea in infancy } \\
\text { Nil } \\
\text { Nil } \\
\text { Mil }\end{array}$ & $\begin{array}{l}>50<75 \\
10 \\
50 \\
50 \\
50 \\
>75<90 \\
50 \\
75\end{array}$ & $\begin{array}{l}>50<75 \dagger \\
>10<25 \\
97 \\
50 \dagger \\
50 \dagger \\
75 \\
50 \dagger \\
75\end{array}$ & $\begin{array}{l}90 \\
90 \\
75 \\
75 \\
75 \\
90 \\
75 \\
50\end{array}$ & $\begin{array}{l}\text { Weekly } \\
\text { Weekly } \\
\text { Weekly } \\
\text { Nil } \\
\text { Nil } \\
\text { Nil } \\
\text { Nil } \\
\text { Daily (1st year } \\
\quad \text { only) }\end{array}$ \\
\hline $\left.\begin{array}{rl}9 & \mathrm{~F} \\
10 & \mathrm{M} \\
11 & \mathrm{~F} \\
12 & \mathrm{M} \\
13 \mathrm{M} \\
14 \mathrm{M} \\
15 \mathrm{M}\end{array}\right\}$ & $\begin{array}{l}2 \cdot 75 \\
1 \cdot 3 \\
2 \cdot 6 \\
1 \cdot 7 \\
1 \cdot 1 \\
1 \cdot 0 \\
0 \cdot 75\end{array}$ & $\begin{array}{l}\text { Photosensitive rash } \\
\text { Nil } \\
\text { Mild diarrhoea in infancy } \\
\text { Fits } \\
\text { Nil } \\
\text { Nil } \\
\text { Nil }\end{array}$ & $\begin{array}{l}50 \\
>25<50 \\
25 \\
25 \\
50 \\
>25<50 \\
>50<75\end{array}$ & $\begin{array}{l}50 \\
50 \\
>10<50 \\
10 \dagger \\
50 \\
25 \\
50\end{array}$ & $\begin{array}{l}90 \\
90 \\
>25<50 \\
>10<25 \\
50 \\
\overline{50}\end{array}$ & $\begin{array}{l}\text { Daily } \\
\text { Daily } \\
\text { Nil } \\
\text { Nil } \\
\text { Nil } \\
\text { Nil } \\
\text { Nil }\end{array}$ \\
\hline
\end{tabular}

* Patients were first diagnosed at age 6-10 weeks, except Case 2 (5 years) and Case 5 (6 years).

† Height centile equal to centile of unaffected sib(s).

Brackets indicate sibships.

\section{Results}

Of 830000 babies tested, 12 were found to have Hartnup disease. 3 of 15 sibs tested were also affected. The findings are summarized in the Table.

Initial urine testing showed a typical aminoaciduria at 6 weeks, except that glycine was markedly increased in Cases 10 and 12. The increase in glycine had disappeared by 16 weeks of age. 5 of the babies (Cases 4, 9, 11, 13, 14) had no increase in indole excretion initially, but all had a variable indoluria at over 6 months of age. Renal clearances of amino acids, determined in Cases 1-6, all showed the typical findings of Hartnup disease as described by Jepson (1972).

The children were followed to the ages of from 9 months to $13 \cdot 7$ years, mean 4.5 years. None of the children had ever suffered from skin rashes or ataxia. Several had had severe intercurrent illnesses (measles, bronchitis, pneumonia) involving more than 2 days in bed (but not more than 3 days with negligible food intake), and had not had any rashes or ataxia at these times. 14 of the 15 did not sunburn easily. One girl (Case 9), aged 2 years, had been treated with nicotinamide, $25 \mathrm{mg} /$ day, since infancy. She suffered very severe sunburn with erythema and blistering, from mild exposure several days after she had run out of nicotinamide tablets. She has not had sunburn since resuming treatment. One boy (Case 12), aged 11 months, not receiving nicotinamide, had petit mal-like fits for one month after mumps. He was treated with an anticonvulsant for 2 months only, and the fits have not recurred.

In 5 children old enough to attend school scholastic achievements were similar to those of their sibs, and each child was rated 'average'. Of 10 chil- dren too young to attend school, 5 were rated by parents as having developed skills as quickly as, or more quickly than, sibs. In 5 there were no unaffected sibs for comparison. Milestones were normal in all cases.

Height centiles of affected children compared with centiles of midparent height are shown in the Table. 10 children had height centiles less than the midparent height centiles. Of these 10, 5 had height centiles which were the same as the centiles of their unaffected siblings (Table). The diet of all children was reported to be a good mixed diet. The weight centiles were close to the height centiles in each case (Table).

\section{Discussion}

Hartnup disease is a disorder of both intestinal and renal tubular transport. No intestinal absorption studies were undertaken in our patients, but the presence of a markedly increased amount of indolic derivatives of tryptophan in the urine suggests that intestinal absorption of tryptophan was indeed impaired.

This study shows that the clinical manifestations of Hartnup disease are uncommon in Australia. Our children were followed for up to $8 \frac{1}{2}$ years. The nutrition of all was good. Several had severe intercurrent illnesses during this time, though in none was there a period of more than 3 days with negligible food intake. All were exposed frequently to strong (Australian) sunlight. The only clinical manifestations possibly related to Hartnup disease are the two incidents recorded above, one of severe sunburn after mild exposure in a child who was temporarily off her usual nicotinamide treatment, and one of 
fits after mumps in a child who never received nicotinamide. The children's mental development appeared normal, but no formal testing was undertaken (see results).

In the 43 cases of Hartnup disease reviewed by Jepson (1972), 28 were reported to suffer from a rash. In 7 the rash was evident by the age of one year. Of 20 cases with ataxia, however, only 2 had this symptom before 5 years of age, but all cases with any symptoms had these by the age of 10 years. At least 9 of the children were retarded. Our follow-up period was relatively short in most cases, with the average age at last review 4.5 years, and only 5 children being of school age. Nevertheless, there is a striking paucity of symptoms in the present series.

The height of the Hartnup children appeared to be below that expected in 10 of 14 cases, and greater than expected in 2 , using midparent height centiles (Tanner et al., 1970). 5 of the 10 who had smaller centiles than the midparent height centiles were nevertheless on the same height centiles as their unaffected sibs. The parents' heights were reported, not measured, heights, and are thus likely to be somewhat inaccurate. Collis et al. (1963) reported on the stature of 8 patients with Hartnup disease, whose heights were obtained by postal enquiry. The mean height, adjusted to the adult male population, was found to be $5 \cdot 3 \mathrm{~cm}$ less than that of normal subjects. Our data, though incomplete, suggest that while affected children may be smaller than expected from measurements of parental heights, the differences are at most very slight.

The incidence of Hartnup disease in the community, based on routine screening of urine from normal infants, has recently been reported by Thalhammer (1975) as part of a collaborative study from three centres: Levy reported an incidence of 1 in 18000 in Massachusetts, Thalhammer 1 in 70000 for Vienna, while in New South Wales we reported an incidence of 1 in 104000 . The discrepancy was so great that we reviewed our findings. It then became clear than in the early years of our survey infants with an aminoaciduria and no indoluria were not given a definitive diagnosis, and the family doctor was invited to arrange follow up. In the latest 300000 babies screened, Hartnup disease was diagnosed according to the criteria described in Methods and there were 3 cases in each 100000 . The incidence in N.S.W. appears to be around 1 in 33000 .

The biochemical abnormality of Hartnup disease seems to be commoner than was formerly thought. The incidence of morbidity is not known, but our study suggests that it is very low and routine treatment does not seem to be indicated when the diet is adequate.

\section{References}

Baron, D. N., Dent, C. E., Harris, H., Hart, E. W., and Jepson, J. B. (1956). Hereditary pellagra-like skin rash with temporary cerebellar ataxia, constant renal aminoaciduria, and other bizarre biochemical features. Lancet, 1, 421-428.

Collis, J. E., Levi, A. J., and Milne, M. D. (1963). Stature and nutrition in cystinuria and Hartnup disease. British Medical Journal, 1, 590-592.

Jepson, J. B. (1972). Hartnup disease. The Metabolic Basis of Inherited Disease, 3rd ed., p. 1486. Ed. by J. B. Stanbury, J. B. Wyngaarden, and D. S. Fredrickson. McGraw Hill, New York.

Tanner, J. M., Goldstein, H., and Whitehouse, R. H. (1970). Standards for children's height at ages 2-9 years allowing for height of parents. Archives of Disease in Childhood, 45, 755-762.

Thalhammer, O. (1975). Frequency of inborn errors of metabolism, especially PKU, in some representative newborn screening centres around the world. A collaborative study. Humangenetik, 30, 273-286.

Turner, B., and Brown, D. A. (1970). Amino acid excretion in infancy and early childhood. A survey of 100,000 infants. Medical Journal of Australia, 1, 11-14.

Wilcken, B., Smith, A., Gaha, T. J., McLeay, A. C., and Brown, D. A. (1973). Screening for metabolic diseases in New South Wales. Medical Journal of Australia, 1, 11291133.

Correspondence to Dr. B. Wilcken, Oliver Latham Laboratory, North Ryde Psychiatric Centre, Sydney, N.S.W., Australia. 